\title{
Experimental investigation of air characteristics during dehumidification in the multilayer desiccant bed column system
}

\author{
Prueksa Sawardsuk ${ }^{1}$, Jiraporn Sripinyowanich Jongyingcharoen ${ }^{2}$ and Ekkapong Cheevitsopon ${ }^{1, *}$ \\ ${ }^{1}$ Department of Food Engineering, Faculty of Engineering, King Mongkut's Institute of Technology Ladkrabang, Bangkok, Thailand \\ ${ }^{2}$ Department of Agricultural Engineering, Faculty of Engineering, King Mongkut's Institute of Technology Ladkrabang, Bangkok, \\ Thailand
}

\begin{abstract}
The gold of this research is to investigate air characteristics during dehumidification process using the multilayer desiccant bed. Silica gel packing in the multilayer column was used as a desiccant material. Airflow direction in the column was designed in a zigzag path passing each desiccant layer. The changes in temperature and relative humidity of exit air were recorded after dehumidification at different airflow rates of 18,36 , and $72 \mathrm{~m}^{3} / \mathrm{h}$. In the desiccant regeneration process, moisture in silica gel was removed by $85^{\circ} \mathrm{C}$ of hot air at varied airflow rates. The characteristics of exit air after regeneration were also monitored. The result revealed that air humidity ratio was significantly decreased using multilayer desiccant bed column. The highest rates of air dehumidification and desiccant regeneration were observed in the first 5 min operation. The highest air dehumidification rate was $12.82 \mathrm{~g} / \mathrm{min}$ at the airflow rate of $72 \mathrm{~m} / \mathrm{h}$ and the highest regeneration rate of desiccant was $6.70 \mathrm{~g} / \mathrm{min}$ at the airflow rate of $72 \mathrm{~m}^{3} / \mathrm{h}$. In addition, the dual column of multilayer desiccant bed can be successfully applied to cyclic operation of dehumidification and regeneration when the cycle time were $5 \mathrm{~min}$ and airflow rate 36 and $72 \mathrm{~m}^{3} / \mathrm{h}$.
\end{abstract}

\section{Introduction}

The desiccant dehumidification of air is widely used in industrials and air conditioning. Either solid or liquid desiccant can be used. However, solid desiccant in forms of packed bed or rotary bed is preferable because of easy handling [1]. The packed bed system has less mechanical problems because its design is not complicate and higher amount of humidity is reduced as compared to the rotary bed system [2,3]. The commonly used solid desiccant is silica gel as it has high moisture adsorption capacity and great pore surface area to trap the water vapor. Adsorption and desorption of the packed bed of silica gel have been reported in several studies. Chang et al. [3] investigated the effect of regeneration conditions on the dehumidification process of modified silica gel and commercial silica gel packed bed. The adsorption of the silica gel was increased as the degree of regeneration increased. Awad et al. [4] fabricated a radial flow dehumidifier using silica gel as a desiccant. Hollow cylindrical bed patterns were designed and test at different diameter ratios. Low bed diameter ratio was appropriate for minimum pressure drop. On the other hand, higher bed diameter ratio caused greater air humidity drop. Dehumidifiers were applied in drying due to many benefits such as reducing drying time and retaining product qualities $[5,6]$.

To date, limited reports are available in the literature on the performance of desiccant bed column. Therefore, the objective of this study was to design the zigzag airflow direction in desiccant bed column, and study the humidity ratio and temperature characteristics of the exit air after dehumidification and regeneration of the air in the multilayer desiccant bed column system. The system was composed of two columns performing the switch task of dehumidification and regeneration, i.e. cyclic operation. The cyclic operation of the system was also carried out at different air flow rates to determine the system performance.

\section{Experiment study}

\subsection{Experimental setup}

A schematic diagram of the multilayer desiccant bed column system is illustrated in Fig. 1. The system consisted of a dual column; column A and column B. Each column was $20 \mathrm{~cm}$ inner diameter and $100 \mathrm{~cm}$ height. Fifteen layers with sieve containers were inside the column. Each layer contained $150 \mathrm{~g}$ of silica gel. The sieve container had an air duct with a diameter of $2.54 \mathrm{~cm}$ to allow the air to pass through. The air duct was changed from left side of one layer to right side of the next layer in order that a zigzag pathway of the air was generated. Outside of the column was covered by rock wool insulation.

\footnotetext{
* Corresponding author: ekkapong.ch@kmitl.ac.th
} 


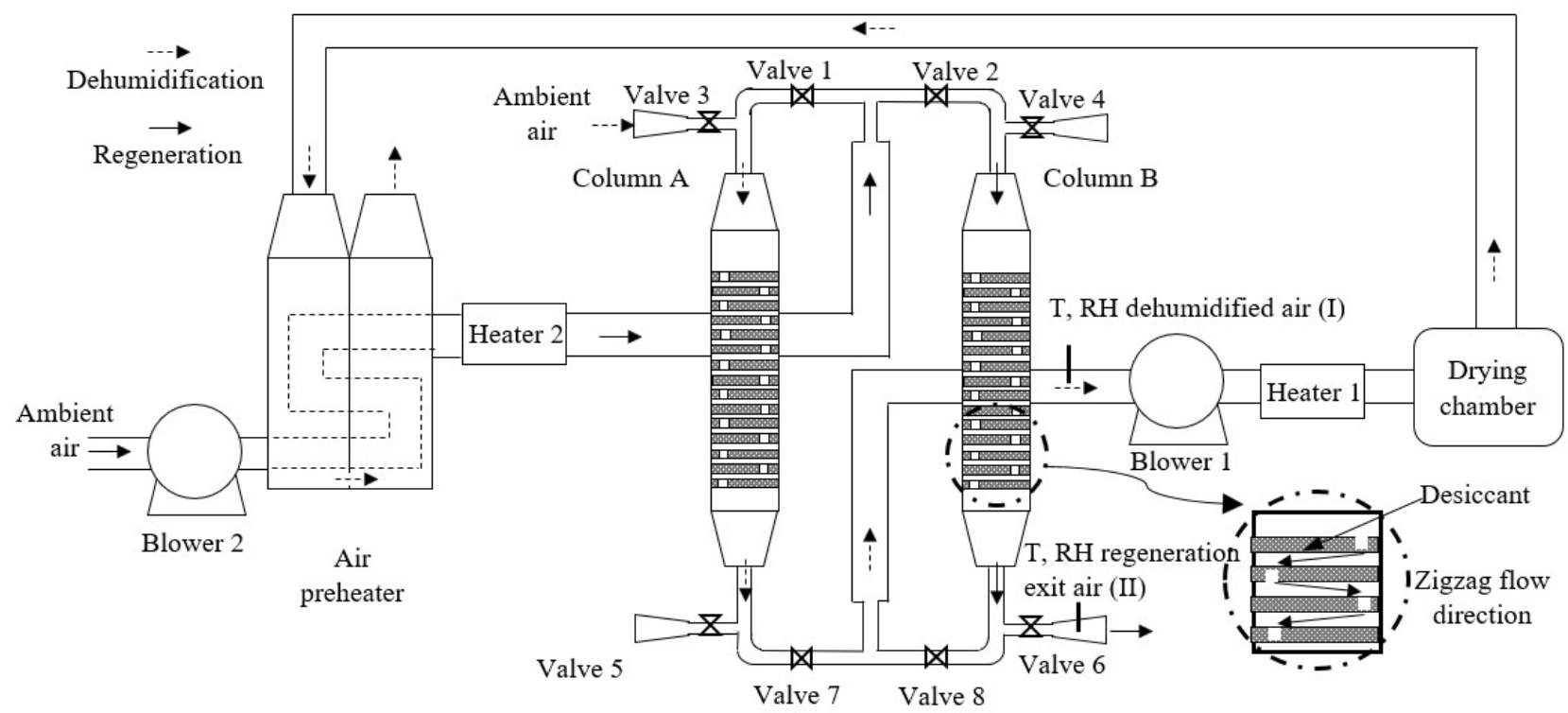

Fig. 1. A schematic diagram of the multilayer desiccant bed column system.

Dehumidification and regeneration operations of the system are shown in Fig. 1 as well. Column A and B were operated alternately between the process of dehumidification of air and regeneration of desiccant. Using column A for dehumidification, valves 3 and 7 were opened while valves 1 and 5 were closed. Ambient air was passed through valve 3 , column $\mathrm{A}$, and valve 7 respectively by blower 1 . Dehumidified air was obtained prior to heating by heater 1 and supplying to a drying chamber. Simultaneously, the desiccant in column B was regenerated. Valves 2 and 6 were opened and valves 4 and 8 were closed. Ambient air was passed through blower 2, preheated by an air preheater, heated to the desirable temperature by heater 2, and used for desiccant regeneration in column $\mathrm{B}$.

\subsection{Instrumentation and experimental procedure}

\subsubsection{Dehumidification and regeneration process}

To prepare fresh silica gel for the dehumidification process, commercial grade silica gel was dried in hot air oven at $90^{\circ} \mathrm{C}$ for $6 \mathrm{~h}$ and allowed to cool in a closed chamber. Saturated silica gel was required for the desiccant regeneration experiment. Silica gel was allowed to adsorb moisture in air at room temperature for $8 \mathrm{~h}$ until its maximum adsorption was reached.

The experiment on air dehumidification and desiccant regeneration were conducted individually. Air flow rates were set at 18,36 and $72 \mathrm{~m}^{3} / \mathrm{h}$ for both experiments. For the regeneration process, air temperature was $85^{\circ} \mathrm{C}$. Temperature and relative humidity of ambient and exit air were recorded every $30 \mathrm{~s}$ for the whole period of $30 \mathrm{~min}$ by temperature hygrometer with the response time of 25 s (KT320, Kimo, France) at point I and II as show in Fig. 1. The dehumidification rate and regeneration rate were calculated by equation (1) and (2), respectively.

$$
\begin{aligned}
\text { Dehumidification rate } & =\dot{m}_{d} \times\left(w_{i, d}-w_{o, d}\right) \\
\text { Regeneration rate } & =\dot{m}_{r} \times\left(w_{o, r}-w_{i, r}\right)
\end{aligned}
$$

Where $\dot{m}$ is mass flow rate of air (kg dry air/min), $\mathrm{w}_{\mathrm{i}}$ and $\mathrm{w}_{\mathrm{o}}$ were humidity ratio of inlet air and exit air ( $\mathrm{g}$ water $/ \mathrm{kg}$ dry air), respectively. The subscript letters of $\mathrm{d}$ and $\mathrm{r}$ are dehumidification and regeneration process, respectively.

Furthermore, specific dehumidification rate and specific regeneration rate were calculated and expressed as dehumidification rate per kilograms of silica gel and regeneration rate per kilograms of silica gel, respectively.

\subsubsection{Cyclic operation process}

To determine performance of the multilayer desiccant bed column system, cyclic operation was performed when alternating the air dehumidification and desiccant regeneration between columns $\mathrm{A}$ and $\mathrm{B}$. Airflow rates varied at 18,36 and $72 \mathrm{~m}^{3} / \mathrm{h}$ for both processes. The regeneration air temperature was $85^{\circ} \mathrm{C}$. One cyclic operation included $5 \mathrm{~min}$ dehumidification and $5 \mathrm{~min}$ regeneration. If column $A$ was used for the dehumidification process, column B was simultaneously used for the regeneration process. The temperature and relative humidity of the exit air from both processes were recorded at the specified interval for $30 \mathrm{~min}$.

\section{Results and discussion}

\subsection{Dehumidification process: Effect of air flow rate on characteristics of the dehumidified air}

Humidity ratio is defined as the proportion of the mass of water vapour to the mass of dry air. It is determined using a psychrometric chart given the data of dry bulb temperature and relative humidity of air. Fig. 2 presents the changes in humidity ratio and temperature of exit air (Point I) after the dehumidification process at the varied airflow rates 18,36 and $72 \mathrm{~m}^{3} / \mathrm{h}$ for $30 \mathrm{~min}$. It can be seen 
that humidity ratio of the exit air sharply decreased at the initial period of dehumidification when compared to humidity ratio of the inlet air (12.09-13.94 g water/g dry air). Thereafter humidity ratio of the exit air increased with increasing time. This was because of lower adsorption capacity of silica gel with longer process time. Similar trend have been observed in a thin multilayer of activated alumina and packed bed of silica gel $[7,8,9]$. At first $5 \mathrm{~min}$ of the process, the highest dehumidification rates were $2.93, \quad 6.52$ and $12.82 \mathrm{~g}$ water $/ \mathrm{min}$ (corresponding to the specific dehumidification rates of $1.30,2.90$ and $5.70 \mathrm{~g}$ water $/(\mathrm{min} \cdot \mathrm{kg}$ silica gel) $)$ at the airflow rates of 18,36 and $72 \mathrm{~m}^{3} / \mathrm{h}$, respectively. Regarding to temperature of the exit air, temperature slightly increased with increasing time because heat was released from the desiccant (heat of adsorption). It could be observed that in long term adsorption, humidity ratio and temperature of the exit air were the same as those of the inlet air. Fig. 3 shows a psychrometric process of air dehumidification at the represent airflow rate of $72 \mathrm{~m}^{3} / \mathrm{h}$. Humidity ratios of the inlet air reduced by about $64 \%$, $50 \%$ and $29 \%$ when the process times were 1,5 and 30 min, respectively. It is interesting that psychrometric path of the dehumidification process at $30 \mathrm{~min}$ conformed to the adiabatic path.

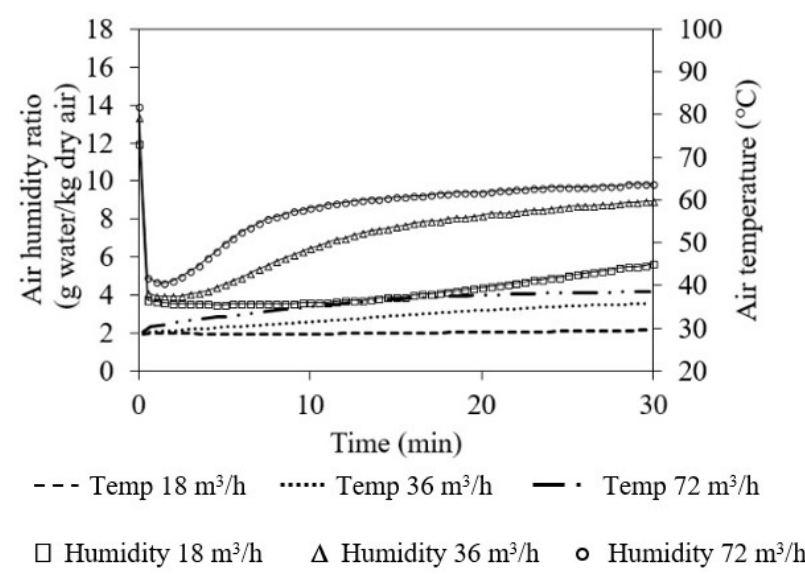

Fig. 2. Humidity ratio and temperature of exit air after the dehumidification process at various airflow rates.

\subsection{Regeneration process: Effect of airflow rate on characteristics of the exit air}

Saturated silica gel was regenerated using the air temperature of $85^{\circ} \mathrm{C}$ at the airflow rates $18-72 \mathrm{~m}^{3} / \mathrm{h}$. The changes in humidity ratio and temperature of the exit air after the regeneration process (Point II) for $30 \mathrm{~min}$ are illustrated in Fig. 4. Humidity ratio of the exit air increased continuously with increasing time. It indicated that moisture in the silica gel was evaporated by the regeneration process. Moreover, the change in humidity ratio of the exit air was dependent on the airflow rate. Humidity ratio of the exit air gradually increased with time at low airflow rate. And the exit air humidity ratio sharply increased with time at high airflow rate. Therefore, the highest regeneration rate was $6.70 \mathrm{~g}$ water/min (corresponding to the specific dehumidification rates of $2.98 \mathrm{~g}$ water/(min.kg silica gel $)$ )

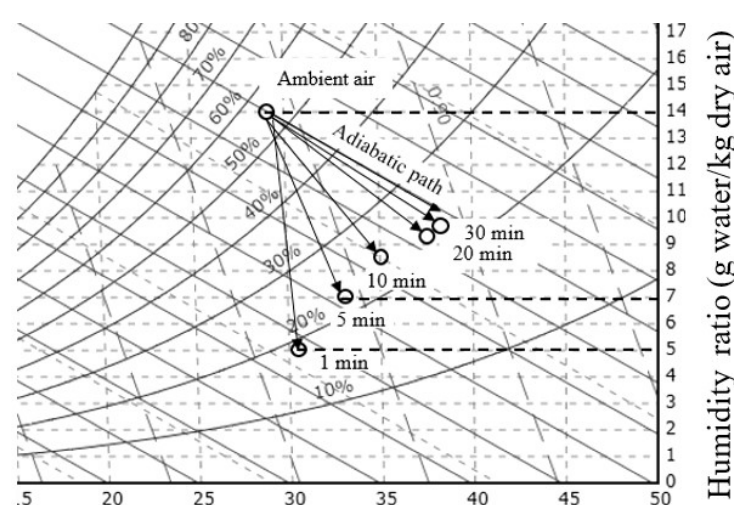

Dry bulb temperature $\left({ }^{\circ} \mathrm{C}\right)$

Fig. 3. Psychrometric paths of the dehumidification process with the airflow rate of $72 \mathrm{~m}^{3} / \mathrm{h}$ at various time.

Fig. 4. Humidity ratio and temperature of exit air after the

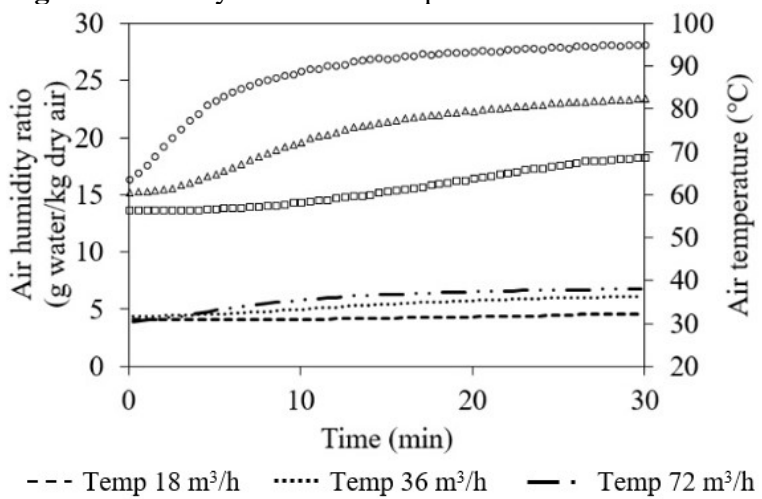

- - - Temp $18 \mathrm{~m}^{3 / \mathrm{h}} \quad$ …. Temp $36 \mathrm{~m}^{3} / \mathrm{h} \quad$ - . Temp $72 \mathrm{~m}^{3} / \mathrm{h}$

口 Humidity $18 \mathrm{~m}^{3} / \mathrm{h} \quad \Delta$ Humidity $36 \mathrm{~m}^{3} / \mathrm{h} \quad$ ○ Humidity $72 \mathrm{~m}^{3} / \mathrm{h}$ regeneration process at various air flow rates.

at the first 5 min when the airflow rate was $72 \mathrm{~m}^{3} / \mathrm{h}$. As can be seen in Fig. 4. temperature of the exit air increased with time. Abou-Ziyan et al. [7] also reported increasing temperature of the exit air for long process period until the temperature was equal to the inlet air temperature.

\subsection{Cyclic operation of the system}

Behaviors of air during the cyclic operation between the dehumidification and regeneration process at the airflow rate 18,36 and $72 \mathrm{~m}^{3} / \mathrm{h}$ are shown in Fig. 5, 6 and 7, respectively. Different characteristics of dehumidification process were found at airflow rate of $18 \mathrm{~m}^{3} / \mathrm{h}$. Humidity ratio of the dehumidification process increased in every cycle. It indicated that moisture was accumulated in the silica gel after the regeneration process. The lowest flow rate of hot air for the regeneration process cannot be applied in this system. For the cyclic operation at the airflow rate of 36 and $72 \mathrm{~m}^{3} / \mathrm{h}$, the humidity ratio of the exit air decreased during dehumidification and increased during regeneration. Similar characteristics were presented in previous research on cyclic operation $[8,10]$. At the airflow rate of $72 \mathrm{~m}^{3} / \mathrm{h}$, humidity ratio of the exit air was the lowest during dehumidification and the highest during regeneration. It should be concluded that the regeneration airflow rate was an important control parameter for a successful cyclic operation. In addition, performance of the cyclic operation was dependent on the cycle duration and air temperature used in the 
regeneration process [7]. When the airflow rate was 72 $\mathrm{m}^{3} / \mathrm{h}$, the multilayer desiccant bed column system could reduce air humidity ratio from the ambient condition (approximately $17 \mathrm{~g}$ water $/ \mathrm{kg}$ dry air) to about $15 \mathrm{~g}$ water $/ \mathrm{kg}$ dry air, yielding $12 \%$ reduction. Therefore, the results indicated that the dual column of the multilayer desiccant bed system could be successfully applied to provide continuous supplied air with low humidity ratio for various industrial processes such as drying.

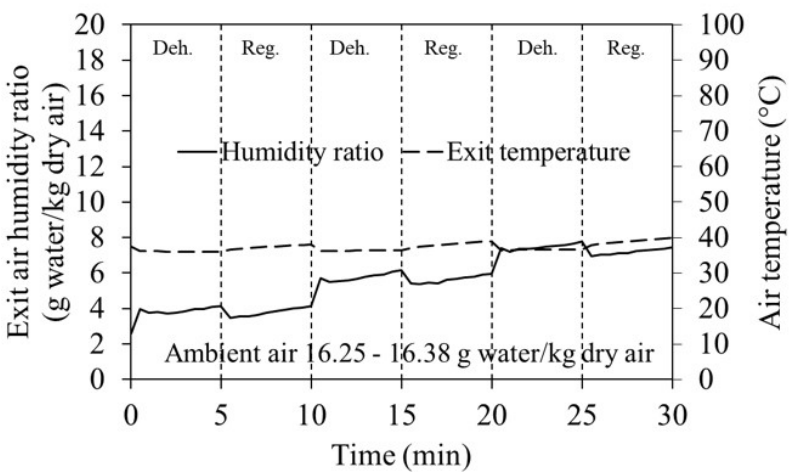

Fig. 5. Humidity ratio and temperature of the exit air during the cyclic operation at $18 \mathrm{~m}^{3} / \mathrm{h}$.

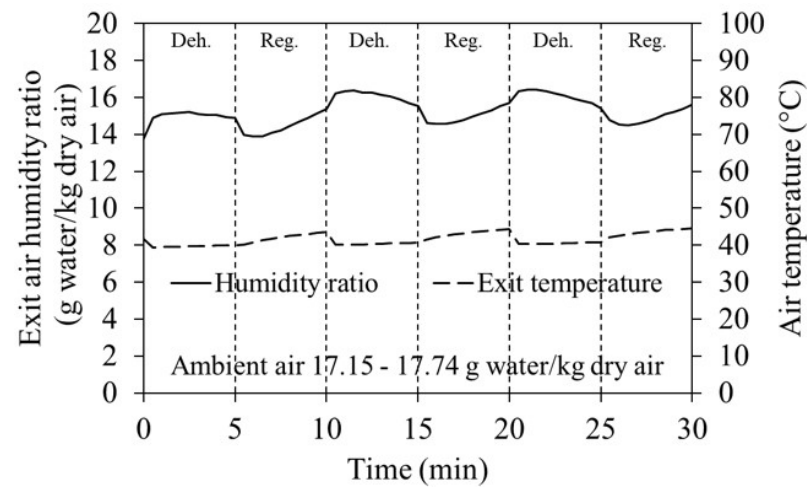

Fig. 6. Humidity ratio and temperature of the exit air during the cyclic operation at $36 \mathrm{~m}^{3} / \mathrm{h}$.

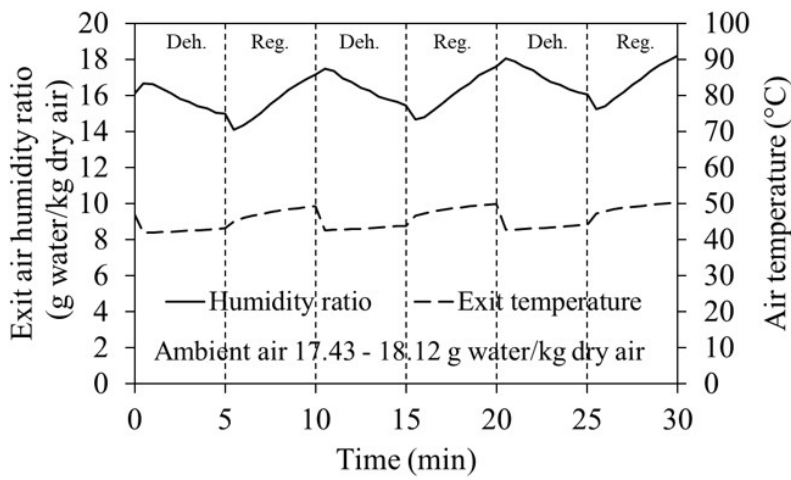

Fig. 7. Humidity ratio and temperature of the exit air during the cyclic operation at $72 \mathrm{~m}^{3} / \mathrm{h}$.

\section{Conclusion}

Air dehumidification and desiccant regeneration of the multilayer desiccant bed column system were studied by observing humidity ratio and temperature of the exit air. Cyclic operation between dehumidification and regeneration was run to test ability of the system. From the study, the following observations can be drawn.
1. The highest dehumidification rate was observed at the beginning of the dehumidification process, and then the dehumidification rate decreased due to lower adsorption capacity of desiccant.

2 . The regeneration rate significantly increased with the airflow rate of hot air.

3 . The cyclic operation at the airflow rates of 36 and $72 \mathrm{~m}^{3} / \mathrm{h}$ presented continuous ability to conduct the dehumidification and regeneration process in the multilayer desiccant bed column system. Humidity ratio of the exit air reduced by about 12\% (compared to humidity ratio of the inlet air) when the airflow rate was $72 \mathrm{~m}^{3} / \mathrm{h}$.

\section{References}

1. S. Misha, S. Mat, M.H. Rustan, K. Sopian, Review of solid/liquid desiccant in the drying applications and its regeneration methods, RENEW SUST ENERG REV 16, 4686 (2001).

2. S.K. Yeboah, J. Darkwa, A critical review of thermal enhancement of packed beds for water vapour adsorption RENEW SUST ENERG REV 58, 1500 (2016).

3. K.S. Chang, H.C. Wang, T.W. Chung, Effect of regeneration condition on the adsorption dehumidification process in packed silica gel beds, Appl. Therm. Eng 24, 735 (2014).

4. M.M. Awad, A. Ramzy K, A.M. Hamed, H.M. Bekheit, Theoretical and experimental investigation on the radial flow desiccant dehumidification bed, Appl. Therm. Eng 28, 75 (2018).

5. K. Nagaya, Y. Li, Z. Jin, M. Fukumuro, Y. Ando. A. Akaishi, Low-temperature desiccant-based food drying system with airflow and temperature control, J Food Eng 75, 71 (2006).

6. G. O. Ondier, T. J. Siebenmorgen, A. Mauromoustakos, Low-temperature, low-relative humidity drying rough rice, J Food Eng 100, 545 (2010).

7. H. Abou-Ziyan, D. Abd El-Raheim, O. Mahmoud, M. Fatouh, Performance characteristics of thinmultilayer activated alumina bed, APPL ENERG 190, 29 (2017).

8. A.K. Ramzy, R. Kadoli, A. Babu T.P., Experimental and theoretical investigation on the cyclic operation of TSA cycle for air dehumidification using packed beds of silica gel, Energy 56, 8 (2013).

9. A.E. Kabeel, Adsorption operations of multilayer desiccant packed bed for dehumidification applications, RENEW ENERG 34, 255 (2009).

10. A.K. Ramzy, A.M. Hamed, M.M.Awad, M.M. Bekheit, Theoretical investigation on the cyclic operation of radial flow desiccant bed dehumidifier, JETR 2, 6 (2010). 